\title{
Movimento do Herbicida Imazapyr no Perfil De Solos Tropicais ${ }^{1}$
}

\author{
Imazapyr Mobility in Tropical Soil Profile
}

\author{
FIRMINO, L.E. ${ }^{2}$, TUFFI SANTOS, L.D. ${ }^{3}$, FERREIRA, L.R. ${ }^{4}$, FERREIRA, F.A. ${ }^{4}$ e QUIRINO, A.L.S. ${ }^{5}$
}

\begin{abstract}
RESUMO - Objetivou-se, no presente trabalho, avaliar a movimentação ascendente e descendente do imazapyr no perfil de três solos tropicais. Utilizaram-se colunas de PVC, formadas pela junção de seis anéis de $5 \mathrm{~cm}$, perfazendo altura total de $30 \mathrm{~cm}$, as quais foram preenchidas com solos muito argiloso, franco-argilo-arenoso e areia-franca. Após aplicação do imazapyr, na dose de $1 \mathrm{~kg} \mathrm{ha}^{-1}$, na superficie das colunas, estas foram submetidas a três condições: simulação de chuva de $14 \mathrm{~mm} / 35 \mathrm{~min}$, seguida de repouso por 48 horas; simulação de chuva de $14 \mathrm{~mm} / 35 \mathrm{~min}$, seguida por repouso de 30 dias; e inversão das colunas após aplicação de imazapyr na superficie, com subirrigação por 20 dias e repouso de 10 dias. Após essa etapa, fez-se o seccionamento das colunas a cada $5 \mathrm{~cm}$ de profundidade. Nos solos provenientes de cada profundidade, semeou-se sorgo como bioindicador, sendo avaliada a massa seca da parte aérea das plantas aos 21 dias após a semeadura. A maior movimentação descendente do imazapyr foi observada no solo areiafranca (até $25 \mathrm{~cm}$ ), seguido pelos solos franco-argilo-arenoso (até $20 \mathrm{~cm}$ ) e muito argiloso (até $15 \mathrm{~cm}$ ). A movimentação ascendente desse herbicida ocorreu junto com a água, ocasionando sua distribuição em toda a extensão da coluna $(30 \mathrm{~cm})$ nos solos franco-argiloarenoso e areia-franca. No solo muito argiloso, o herbicida movimentou-se cerca de $25 \mathrm{~cm}$ na vertical ascendente. O imazapyr apresentou alta mobilidade nos três solos, junto com o movimento da água no perfil, tanto no sentido ascendente como no descendente. Essa alta mobilidade pode levar à contaminação de corpos d'água, bem como ocasionar ciclos de permanência do produto nas camadas mais superficiais, de acordo com a disponibilidade de umidade no solo.
\end{abstract}

Palavras-chave: comportamento no solo, lixiviação, bioensaio, herbicida.

\begin{abstract}
The experiment was carried out in columns filled with three different tropical soils, (very clayey soil, sand loam soil and sand clay loam soil) to evaluate ascending and descending movement of imazapyr. After applying $1 \mathrm{~kg} \mathrm{ha-1}$ of the herbicide on each column surface, columns were submitted to three conditions: 1) $14 \mathrm{~min} / 35 \mathrm{~min}$ rainfall simulation followed by 48 hours rest; 2) $14 \mathrm{~min} / 35 \mathrm{~min}$ rainfall simulation followed by 30 days rest; and column inversion after applying imazapyr on the surface, under sub irrigation during 20 days, followed by 10 days rest. After this stage, columns were sectioned every $5 \mathrm{~cm}$ of depth. Sorghum bicolor was sowed as bioindicator on each portion and after 20 days of sowing, dry matter of the above ground tissue was evaluated. The higher herbicide descending movement observed was in sandy loam soil, followed by sandy clay loam and clay soil. The ascending movement of this herbicide occurred together with water, causing herbicide distribution in all the column area in sandy clay loam and sandy loam soils, while clay soil showed a smaller ascending movement. Imazapyr presents high mobility on all three soils, together with water movement in the soil profile, both in ascending and descending motions. Such high mobility may cause ground water contamination, and also cycles of permanence of this product in the superficial layers of the soil, depending on humidity availability.
\end{abstract}

Keywords: soil behavior, leaching, bioassay, herbicide

1 Recebido para publicação em 13.9.2007 e na forma revisada em 4.1.2008.

2 Mestre em Fitotecnia; ${ }^{3}$ Pós-doutorando do Dep. de Fitotecnia <ltuffi@yahoo.com.br>; ${ }^{4}$ Professor do Dep. de Fitotecnia;

${ }^{5}$ Engo-Agrơ ${ }^{\circ}$ Universidade Federal de Viçosa, Dep. de Fitotecnia, Av. PH Rolfs, s/n, 36570-000 Viçosa-MG. 


\section{INTRODUÇÃO}

O comportamento de um herbicida no solo é influenciado por processos de retenção, transformação e transporte do produto. A mobilidade do herbicida no solo - que influencia diretamente o seu desempenho no controle de plantas daninhas e a sua dissipação no ambiente - pode ser avaliada por diferentes métodos (Silva et al., 2007). Entretanto, métodos que melhor se aproximem das condições de campo e que apresentem boa reprodutibilidade são os mais adequados para esse tipo de estudo. Considerando os herbicidas derivados das imidazolinonas, o método da coluna de lixiviação tem sido amplamente utilizado (Liu \& Weber, 1985; Mckinnon \& Weber, 1988; Mangels, 1991; Souza et al., 2000; Rossi et al., 2005), apresentando bons resultados.

Parte do herbicida que atinge o solo pode ser transportada para o seu interior, junto com a água proveniente das chuvas ou de irrigações. Uma vez na solução do solo, o herbicida recebe a atuação de forças, como a difusão no interior dos agregados, a ação da capilaridade promovida pela evaporação da água na superfície do solo e a sorção pelos colóides. Esses processos são influenciados pela molécula do herbicida, pela intensidade das precipitações/ irrigações e pelos fatores sazonais (Silva et al., 2007). A possibilidade de movimento ascendente (lixiviação reversa) do herbicida lixiviado deve também ser considerada. Esse fato se torna mais evidente no caso dos herbicidas fracamente adsorvidos, como o imazapyr, principalmente sob condições de elevada evapotranspiração (Mangels, 1991).

O imazapyr apresenta amplo espectro de controle de plantas daninhas anuais e perenes, podendo ser aplicado em pré e em pósemergência (Lee et al., 1991). A atividade biológica e o seu movimento no perfil são bastante influenciados pelas características do solo e pelas condições climáticas. Dentre esses fatores, a textura, o tipo de argila, a umidade e o $\mathrm{pH}$ do solo influenciam diretamente a sorção e, conseqüentemente, a mobilidade do imazapyr no perfil do solo (Souza et al., 2000). O imazapyr apresenta maior lixiviação no solo arenoso, em relação ao solo de textura argilosa, com diminuição da sua mobilidade com a redução da umidade e do $\mathrm{pH}$ do substrato (Souza et al., 2000). A sorção desse herbicida é bastante influenciada pelo $\mathrm{pH}$, pela carga do componente adsorvente e pela presença de óxidos de ferro amorfo e matéria orgânica, em $\mathrm{pH}<5$ (Pusino et al., 1997).

Em razão da diversidade de respostas desse herbicida nos diferentes tipos de substrato e da escassez de informações em ambientes tropicais, objetivou-se com este trabalho avaliar o movimento vertical descendente e ascendente do imazapyr no perfil de três solos com diferentes características químicas e texturais.

\section{MATERIAL E MÉTODOS}

Para estudo do movimento do imazapyr foram utilizados três solos provenientes de Rio Casca (RC), João Pinheiro (JP) e Sete Lagoas (SL), cujas análises química e física encontram-se na Tabela 1. As amostras foram coletadas na camada superficial de 0 a $20 \mathrm{~cm}$, secas ao ar e passadas em peneiras de $2,0 \mathrm{~mm}$ de abertura de malha.

As colunas para lixiviação utilizadas no estudo foram formadas pela junção de seis anéis de PVC de $5 \mathrm{~cm}$ de altura e $10 \mathrm{~cm}$ de diâmetro. Logo após a montagem das colunas, suas paredes internas foram parafinadas, antes de receberem o solo, criando uma camada hidrofóbica. Esse procedimento foi realizado a fim de evitar o fluxo de água pelas paredes das colunas. Posteriormente, discos de papel-filtro (INLAB - no 10 - porosidade de $10 \mu \mathrm{m}$ ) de $11 \mathrm{~cm}$ de diâmetro e uma malha de gaze (abertura de malha de $10 \mathrm{~mm}$ ), presa por elástico, foram colocados na parte inferior da coluna, para reter o solo.

Após seu preparo, as colunas foram totalmente preenchidas até o topo com os diferentes solos, evitando-se camadas compactadas ao longo da junção dos anéis de PVC. As colunas que continham os materiais de solo foram colocadas na posição vertical, em bandejas com água destilada, durante 60 horas, tempo suficiente para saturação por capilaridade. Após esse período, o excesso de água foi drenado, deixando as colunas com a superficie superior vedada com plástico sobre a bancada por 48 horas - tempo suficiente para que a umidade do solo permanecesse próxima à capacidade 
Tabela 1 - Resultados das análises química e física das amostras dos solos provenientes dos municípios de Sete Lagoas (SL), João Pinheiro (JP) e Rio Casca (RC), no Estado de Minas Gerais

\begin{tabular}{|c|c|c|c|c|c|c|c|c|}
\hline \multicolumn{9}{|c|}{ Caracterização química } \\
\hline \multirow{2}{*}{$\begin{array}{l}\text { Origem } \\
\text { do solo }\end{array}$} & \multirow{2}{*}{$\mathrm{pH}$} & $\mathrm{P}$ & $\mathrm{K}$ & A & $\mathrm{H}+\mathrm{Al}$ & $\mathrm{Ca}$ & $\mathrm{Mg}$ & $\mathrm{CO}$ \\
\hline & & \multicolumn{2}{|c|}{$--\mathrm{mg} \mathrm{dm}^{-3}--$} & \multicolumn{4}{|c|}{-------------------------- $\mathrm{cmol}_{\mathrm{c}} \mathrm{dm}^{-3}$---------------------- } & --- dag $\mathrm{kg}^{-1}$--- \\
\hline SL & 5,21 & 3,36 & 80 & 0 , & 9,60 & 1,04 & 0,19 & 3,20 \\
\hline JP & 4,95 & 1,20 & 30 & 1 , & 4,50 & 0,10 & 0,35 & 1,20 \\
\hline \multirow[t]{3}{*}{$\mathrm{RC}$} & 6,28 & 2,77 & 69 & 0 , & 1,32 & 2,29 & 0,73 & 1,14 \\
\hline & \multicolumn{3}{|c|}{ Fe oxalato } & \multicolumn{2}{|c|}{ Fe ditionito } & \multicolumn{3}{|c|}{ P remanescente } \\
\hline & \multicolumn{5}{|c|}{------------------- dag kg ${ }^{-1}$--------------------- } & \multicolumn{3}{|c|}{------------ $\mathrm{mg} \mathrm{L}^{-1}$------------- } \\
\hline SL & \multicolumn{3}{|c|}{0,57} & \multicolumn{2}{|c|}{6,84} & \multicolumn{3}{|c|}{5,18} \\
\hline JP & \multicolumn{3}{|c|}{0,41} & \multicolumn{2}{|c|}{5,65} & \multicolumn{3}{|c|}{18,09} \\
\hline $\mathrm{RC}$ & \multicolumn{3}{|c|}{0,08} & \multicolumn{2}{|c|}{0,42} & \multicolumn{3}{|c|}{39,70} \\
\hline \multicolumn{9}{|c|}{ Caracterização física } \\
\hline & Argila & \multicolumn{2}{|c|}{ Silte } & a fina & Areia grossa & \multirow{2}{*}{\multicolumn{3}{|c|}{ Classificação textural }} \\
\hline & \multicolumn{5}{|c|}{ 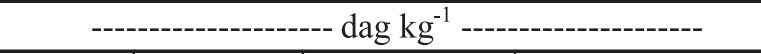 } & & & \\
\hline SL & 81 & \multicolumn{2}{|l|}{5} & \multicolumn{2}{|l|}{5} & \multicolumn{3}{|c|}{ Muito argilosa } \\
\hline JP & 30 & \multicolumn{2}{|l|}{6} & \multicolumn{2}{|l|}{22} & \multicolumn{3}{|c|}{ Franco-argilo-arenosa } \\
\hline $\mathrm{RC}$ & 10 & 5 & & 9 & 76 & \multicolumn{3}{|c|}{ Areia-franca } \\
\hline
\end{tabular}

Análises realizadas nos Laboratórios de Análises Físicas e Químicas de Solo do Departamento de Solos da UFV.

de campo. Posteriormente, o herbicida foi aplicado na superficie das colunas, uniformemente, utilizando uma seringa de $5 \mathrm{~mL}$, adaptada, com a extremidade da agulha em forma de leque. A dose de imazapyr aplicada foi equivalente a $1,0 \mathrm{~kg} \mathrm{ha}^{-1}$ do ingrediente ativo. Após aplicação do herbicida, dois terços das colunas (24 colunas) foram submetidos à chuva simulada de $14 \mathrm{~mm}$, por 35 minutos.

Doze dessas colunas, com 48 horas após simulação de chuva, foram seccionadas a cada $5 \mathrm{~cm}$, nas junções dos anéis de PVC, sendo o solo, correspondente a cada profundidade, coletado para realização do bioensaio. Esse grupo de colunas caracterizou a "condição 1" (colunas submetidas à aplicação de imazapyr, com $14 \mathrm{~mm}$ de chuva por 35 minutos e repouso de 48 horas).

As outras 12 colunas, que também receberam a simulação de chuva (lixiviação), foram deixadas em casa de vegetação, onde permaneceram em repouso com a superficie livre, para haver evaporação, na posição vertical, por um periodo de 30 dias. Em seguida, foram seccionadas, procedendo-se como descrito anteriormente. Este grupo de colunas caracterizou a "condição 2" (colunas submetidas a $14 \mathrm{~mm}$ de chuva por 35 minutos, mantidas em repouso por 30 dias).

As 12 colunas restantes, que não receberam chuva, após aplicação do herbicida na superficie, foram imediatamente invertidas, de maneira que a parte superior onde foi aplicado o herbicida passou a ser a base. Elas foram colocadas sobre uma placa de Petri de $15 \mathrm{~cm}$ de diâmetro, sendo a irrigação feita por uma pequena mangueira de $15 \mathrm{~cm}$ de comprimento e $5 \mathrm{~mm}$ de diâmetro. O espaço entre a coluna e a placa de Petri foi vedado com plástico e fita adesiva, para evitar perda de água por evaporação. Essas colunas foram deixadas em casa de vegetação, recebendo continuamente irrigação na base por 20 dias, sendo seccionadas dez dias após este período, perfazendo um total de 30 dias após a aplicação. O topo da coluna permaneceu livre de qualquer proteção, para permitir a evaporação e o movimento vertical ascendente da água colocada na sua base. Essas colunas caracterizaram a "condição 3" (colunas que tiveram o herbicida aplicado na superficie, sendo invertidas e submetidas à irrigação na base por 20 dias e repouso por 
10 dias). As colunas desse grupo também foram preparadas para realização do bioensaio, como descrito anteriormente.

O experimento foi instalado num esquema de parcelas subdivididas, tendo nas parcelas um esquema fatorial $3 \times 3$ (três tipos de solo e três condições a que foram submetidas as colunas) e nas subparcelas as profundidades nas colunas $(0$ a $5 ; 5$ a $10 ; 10$ a $15 ; 15$ a 20; 20 a 25 ; e 25 a $30 \mathrm{~cm}$ ), no delineamento inteiramente casualizado, com quatro repetições.

As amostras coletadas em cada profundidade das colunas foram homogeneizadas e colocadas em vasos de polietileno (capacidade para $350 \mathrm{~cm}^{3}$ ) recobertos internamente com sacos plásticos. Nessas mesmas condições, também foram colocadas amostras de cada solo sem herbicida (testemunha), a título de comparação. Em seguida, fez-se a semeadura de oito sementes por vaso de sorgo BR 007 (Sorghum bicolor), a uma profundidade de $1,5 \mathrm{~cm}$. Após a semeadura da planta-teste, simulou-se chuva de $10 \mathrm{~mm}$, durante três minutos, para todos os vasos. O teor de umidade foi mantido praticamente constante até a colheita da planta-teste, para permitir o máximo crescimento e a maior disponibilidade do herbicida na solução do solo. As irrigações para manutenção da umidade dos vasos foram feitas três vezes ao dia.

Aos 21 dias após a semeadura, colheramse as plantas de sorgo, anotando o número de indivíduos por vaso, e, em seguida, foi cortada a parte aérea rente ao solo, para determinação da massa seca. Os dados de massa seca da parte aérea da planta de sorgo foram transformados em porcentagem de crescimento em relação à testemunha, de maneira que os valores próximos a $100 \%$ correspondessem a crescimento semelhante ao da testemunha.

\section{RESULTADOS E DISCUSSÃO}

O crescimento da planta-teste, expresso em porcentagem em relação à testemunha, apresentou diferenças $(\mathrm{P}<0,05)$ em função do solo, das condições a que foram submetidas as colunas e da interação entre os fatores, dentro da parcela experimental. A análise de variância também mostrou efeito significativo da profundidade do solo (locada na subparcela) sobre o crescimento do bioindicador, bem como da interação entre solo $\mathrm{x}$ condições das colunas $\mathrm{x}$ profundidade (Tabela 2), sendo realizado o desdobramento dessa interação.

Tabela 2 - Resumo das análises de variância relativo ao acúmulo de biomassa seca (porcentagem de crescimento em relação à testemunha) de plantas de sorgo cultivadas em amostras de solos, provenientes das diversas profundidades nas colunas, expostas ao imazapyr

\begin{tabular}{|l|r|c|}
\hline Fonte de variação & GL & Quadrado médio \\
\hline Solo & 2 & $2.811,3 * *$ \\
\hline Condições (Cond) & 2 & $7.152,4 * *$ \\
\hline Cond * Solo & 4 & $972,8^{*}$ \\
\hline Resíduo (a) & 27 & 296,1 \\
\hline Profundidade (Prof) & 5 & $10.474,1^{* *}$ \\
\hline Prof * Solo & 10 & $719,1^{* *}$ \\
\hline Prof * Cond & 10 & $9.993,3^{* *}$ \\
\hline Prof * Cond * Solo & 20 & $951,8^{* *}$ \\
\hline Resíduo (b) & 135 & 203,9 \\
\hline CV (\%) subparcela & & 30,5 \\
\hline CV (\%) parcela & & 25,3 \\
\hline
\end{tabular}

$* *, *$ Significativo a 1 e $5 \%$ de probabilidade, respectivamente, pelo teste $\mathrm{F}$

Maior intoxicação aparente foi encontrada em amostras de solos provenientes das profundidades de 0 a $15 \mathrm{~cm}$ para o solo muito argiloso (SL); de 0 a $20 \mathrm{~cm}$, para o solo franco-argiloarenoso (JP); e de 0 a $25 \mathrm{~cm}$, para o solo areiafranca $(\mathrm{RC})$.

O crescimento das plantas de sorgo após aplicação de imazapyr na superfície das colunas, seguida de simulação de $14 \mathrm{~mm}$ de chuva com repouso de 48 horas (condição 1), pode ser observado na Tabela 3. Nessas condições, o crescimento do sorgo, expresso em massa seca (g), é diferenciado entre solos tratados com imazapyr (Tabela 3). No solo muito argiloso (SL) houve diferença entre a massa seca das plantas de sorgo observada nas profundidades de 0 a $15 \mathrm{~cm}$ e as médias nas profundidades de 15 a $30 \mathrm{~cm}$, nas quais foram encontrados valores próximos aos da testemunha (Tabela 3), o que indica niveis muito baixos ou ausência de imazapyr nas camadas mais profundas das colunas. Para os solos franco-argilo-arenoso (JP) e areia-franca $(\mathrm{RC})$, observou-se menor crescimento do sorgo nas profundidades de 0 a $20 \mathrm{~cm}$, 
Tabela 3 - Valores médios da massa seca (porcentagem de crescimento em relação à testemunha) da parte aérea de plantas de sorgo cultivadas em três solos submetidos à aplicação de imazapyr, seguida de $14 \mathrm{~mm}$ de chuva por 35 minutos e repouso de 48 horas

\begin{tabular}{|c|c|c|c|}
\hline \multirow{2}{*}{$\begin{array}{c}\text { Profundidade na coluna } \\
(\mathrm{cm})\end{array}$} & \multicolumn{3}{|c|}{ Porcentagem de acúmulo de biomassa seca da parte aérea em relação à testemunha } \\
\cline { 2 - 4 } & \multicolumn{3}{|c|}{ Solos } \\
\cline { 2 - 4 } & Muito argiloso (SL) & Franco-argilo-arenoso (JP) & Areia-franca (RC) \\
\hline $0-5$ & $14,9 \mathrm{~B} \mathrm{~b}$ & $53,5 \mathrm{C} \mathrm{D} \mathrm{a}$ & $17,5 \mathrm{C} \mathrm{b}$ \\
\hline $5-10$ & $13,8 \mathrm{~B} \mathrm{a}$ & $35,6 \mathrm{D} \mathrm{a}$ & $17,5 \mathrm{C} \mathrm{a}$ \\
\hline $10-15$ & $36,3 \mathrm{~B} \mathrm{a}$ & $32,9 \mathrm{D} \mathrm{a}$ & $30,2 \mathrm{C} \mathrm{c}$ \\
\hline $15-20$ & $102,6 \mathrm{~A} \mathrm{a}$ & $70,3 \mathrm{~B} \mathrm{C} \mathrm{b}$ & $65,6 \mathrm{~B} \mathrm{~b}$ \\
\hline $20-25$ & $106,4 \mathrm{~A} \mathrm{a}$ & $105,1 \mathrm{~A} \mathrm{a}$ & $99,9 \mathrm{~A} \mathrm{a}$ \\
\hline $25-30$ & $95,4 \mathrm{~A} \mathrm{a}$ & $96,9 \mathrm{~A} \mathrm{a}$ & 36,59 \\
\hline $\mathrm{CV}(\%)$ & 27,26 & 18,45 & $\mathrm{C}$ \\
\hline
\end{tabular}

As médias seguidas de pelo menos uma mesma letra, maiúscula na coluna e minúscula na linha, não diferem entre si pelo teste de Tukey a $5 \%$ de probabilidade.

indicando presença de imazapyr em niveis tóxicos para planta-teste ao longo desta camada do perfil dos solos (Tabela 3). Entretanto, no solo areia-franca, as plantas cultivadas no substrato proveniente da profundidade de 20 a $25 \mathrm{~cm}$, embora tenham mostrado média superior à da camada de 0 a $20 \mathrm{~cm}$, apresentaram média igual a 65,6\% de crescimento em relação à testemunha, indicando também a presença do herbicida. Nos solos franco-argilo-arenoso (JP) e areia-franca (RC) não foi detectada a presença do herbicida nas profundidades de 20 - 30 e $25-30 \mathrm{~cm}$, respectivamente. Nas profundidades de $15-20$ e $20-25 \mathrm{~cm}$, menor crescimento das plantas de sorgo foi observado no solo areia-franca, indicando maiores concentrações do imazapyr que no solo francoargilo-arenoso.

Os três solos mantidos na condição 2 (aplicação do imazapyr com posterior simulação da chuva e manutenção das colunas em repouso durante 30 dias sem irrigação) apresentaram toxidez, causada pelo herbicida, para as plantas de sorgo quando cultivadas em amostras provenientes das camadas mais superficiais das colunas (Tabela 4). Nessas condições, o imazapyr percolou no perfil dos solos muitoargiloso (SL), franco-argilo-arenoso (JP) e areiafranca $(\mathrm{RC})$ nas respectivas profundidades de 0-10, 0-20 e 0-20 no sentido descendente, causando diminuição no crescimento do bioindicador (Tabela 4).

A movimentação descendente do imazapyr, após a chuva simulada, apresenta a seguinte ordem decrescente: areia-franca > franco-argilo-arenoso > muito argiloso (Tabela 3). Entretanto, quando do repouso do solo dentro das colunas por período de 30 dias, não se observou diferença entre os solos franco-argilo-arenoso (JP) e areia-franca (RC) na movimentação descendente desse herbicida (Tabela 4). A menor movimentação do imazapyr no solo muito argiloso (SL) pode ser atribuída às suas propriedades físico-químicas: alto teor de $\mathrm{CO}\left(3,2 \mathrm{dag} \mathrm{kg}^{-1}\right)$ e de argila (81 dag $\mathrm{kg}^{-1}$ ) e baixo valor de $\mathrm{pH}$ $(5,21)$. Solos muito argilosos apresentam maior valor de $\mathrm{I}_{50}$, bem como maior razão de sorção, o que indica maior sorção do imazapyr nessas condições (Firmino, 2001). A textura muito argilosa do solo proveniente de Sete Lagoas dificulta a movimentação da água no perfil, o que contribuiu para menor movimentação descendente do imazapyr em relação aos solos de textura mais arenosa.

Em estudo sobre o potencial de lixiviação de herbicidas comercializados no Estado do Paraná, de acordo com os índices de GUS (Gustafson, 1989), CDFA (Widerson \& Kim, 1986) e Cohen (Cohen et al., 1984), o imazapyr foi dado como lixiviador pelos três critérios (Inoue et al., 2003). A lixiviação do imazapyr nos solos e a capacidade deste de ser exsudado pelo sistema radicular de plantas tratadas com este produto, como relatado em alguns trabalhos (Silva et al., 2005; Souza et al., 2006), possibilitam a distribuição desse herbicida ao longo do perfil do solo. No caso de plantas com raízes profundas, a exsudação, juntamente 
Tabela 4 - Valores médios do acúmulo de massa seca da parte aérea das plantas de sorgo cultivadas em amostras de três solos submetidas à aplicação de imazapyr, seguida de $14 \mathrm{~mm}$ de chuva por 35 minutos e de repouso por 30 dias (condição 2)

\begin{tabular}{|c|c|c|c|}
\hline \multirow{2}{*}{$\begin{array}{c}\text { Profundidade na coluna } \\
(\mathrm{cm})\end{array}$} & \multicolumn{3}{|c|}{ Porcentagem de acúmulo de biomassa seca da parte aérea em relação à testemunha } \\
\cline { 2 - 4 } & \multicolumn{3}{|c|}{ Solos } \\
\cline { 2 - 4 } & Muito argiloso (SL) & Franco-argilo-arenoso (JP) & Areia-franca (RC) \\
\hline $0-5$ & $11,6 \mathrm{~B} \mathrm{a}$ & $29,4 \mathrm{D} \mathrm{a}$ & $17,9 \mathrm{C} \mathrm{a}$ \\
\hline $5-10$ & $36,1 \mathrm{~B} \mathrm{a}$ & $31,4 \mathrm{D} \mathrm{a}$ & $34,7 \mathrm{~B} \mathrm{C} \mathrm{a}$ \\
\hline $10-15$ & $80,3 \mathrm{~A} \mathrm{a}$ & $49,5 \mathrm{D} \mathrm{C} \mathrm{b}$ & $76,9 \mathrm{AB} \mathrm{a} \mathrm{b}$ \\
\hline $15-20$ & $102,9 \mathrm{~A} \mathrm{a}$ & $74,3 \mathrm{~B} \mathrm{C} \mathrm{b}$ & $91,8 \mathrm{~A} \mathrm{a}$ \\
\hline $20-25$ & $93,0 \mathrm{~A} \mathrm{a}$ & $85,5 \mathrm{~A} \mathrm{~B} \mathrm{a}$ & $108,1 \mathrm{~A} \mathrm{a}$ \\
\hline $25-30$ & $96,3 \mathrm{~A} \mathrm{a}$ & $114,3 \mathrm{~A} \mathrm{a}$ & 32,02 \\
\hline $\mathrm{CV}(\%)$ & 41,10 & 17,23 & \\
\hline
\end{tabular}

Médias seguidas de pelo menos uma mesma letra, maiúscula na coluna e minúscula na linha, não diferem entre si pelo teste de Tukey a $5 \%$ de probabilidade.

com a lixiviação do produto, pode facilitar a contaminação do lençol freático pelo imazapyr.

No solo muito argiloso (SL), tratado com imazapyr, com simulação de $14 \mathrm{~mm}$ de chuva por 35 minutos e 48 horas de repouso (condição 1), o herbicida foi detectado em níveis tóxicos ao sorgo até $15 \mathrm{~cm}$. Quando o repouso foi de 30 dias (condição 2), mantendo-se as colunas na posição vertical, o imazapyr foi detectado apenas até $10 \mathrm{~cm}$ de profundidade. Esses resultados caracterizam a movimentação ascendente do imazapyr (lixiviação reversa), juntamente com a água, que se movimenta por capilaridade, em virtude da evaporação, na camada superficial. Esta observação fica reforçada quando se verifica que as plantas de sorgo em amostras de solos coletadas na profundidade de 10 a $15 \mathrm{~cm}$, para a condição 1 , cresceram $36,3 \%$ (Tabela 3) e, para a condição 2, 80,3\% em relação à testemunha cultivada nesse solo (Tabela 4). A movimentação ascendente do imazapyr também ocorre nos solos areia-franca (RC) e franco-argilo-arenoso (JP).

Não houve diferença entre as médias do crescimento das plantas-teste de 0 a 5 e 5 a $10 \mathrm{~cm}$ nos três solos, o que indica concentrações de imazapyr semelhantes nessas profundidades (Tabela 4). Não houve diferença entre as médias do crescimento das plantas nos três solos retirados a 20 a 25 ou 25 a $30 \mathrm{~cm}$ de profundidade. Apesar de não diferir das demais, a média observada para o solo franco-argiloarenoso (JP) (85,5\%), na profundidade de 20 a
$25 \mathrm{~cm}$, indica presença de imazapyr em baixa concentração (Tabela 5), mas ainda tóxico ao sorgo.

Os resultados da aplicação de imazapyr na superficie das colunas, sendo estas invertidas e submetidas à irrigação na base por 20 dias, seguida de 10 dias de repouso (condição 3), podem ser observados na Tabela 5. O imazapyr influenciou o crescimento das plantas cultivadas em todas as amostras de solo até $25 \mathrm{~cm}$ de altura na coluna (a partir da base), indicando alta mobilidade vertical, mesmo no solo muito argiloso (SL) (Tabela 5). A ascensão do imazapyr ocorreu junto com a água de irrigação aplicada na base das colunas. O movimento ascendente do herbicida ocorreu em todos os solos, mas foi menor no solo muito argiloso (SL) (Tabela 5). Nos solos franco-argilo-arenoso (JP) e areia-franca $(\mathrm{RC})$, a distribuição do imazapyr ao longo de toda a coluna foi uniforme, não se observando diferenças no crescimento das plantas de sorgo (Tabela 5). O movimento ascendente do imazapyr juntamente com a água foi facilitado pela baixa capacidade sortiva desses solos, aliado às propriedades físico-químicas do herbicida.

Ao comparar, em relação à testemunha, o crescimento da planta-teste nos diferentes solos na amostra coletada de 0 a $5 \mathrm{~cm}$, observou-se crescimento semelhante ao da testemunha, indicando concentração muito baixa ou ausência do imazapyr para o solo muito argiloso (SL). Nas mesmas condições, o 
Tabela 5 - Valores médios de crescimento de plantas de sorgo cultivadas em amostras de três solos provenientes das colunas submetidas à aplicação de imazapyr na superfície, que, após serem invertidas receberam irrigação na base por 20 dias

\begin{tabular}{|c|c|c|c|}
\hline \multirow{3}{*}{$\begin{array}{l}\text { Profundidade na coluna } \\
\qquad(\mathrm{cm})\end{array}$} & \multicolumn{3}{|c|}{ Porcentagem de acúmulo de biomassa seca da parte aérea em relação à testemunha } \\
\hline & \multicolumn{3}{|c|}{ Solos } \\
\hline & Muito argiloso (SL) & Franco-argilo-arenoso (JP) & Areia-franca (RC) \\
\hline $0-5$ & $99,9 \mathrm{~A} \mathrm{a}$ & $67,5 \mathrm{~A} \mathrm{~b}$ & $45,3 \mathrm{~A} \mathrm{~b}$ \\
\hline $5-10$ & $64,6 \mathrm{~B} \mathrm{a}$ & $54,2 \mathrm{~A} \mathrm{~B} \mathrm{a}$ & $44,5 \mathrm{~A} \mathrm{a}$ \\
\hline $10-15$ & $55,4 \mathrm{~B} \mathrm{C} \mathrm{a}$ & $56,8 \mathrm{~A} \mathrm{~B} \mathrm{a}$ & $43,3 \mathrm{~A} \mathrm{a}$ \\
\hline $15-20$ & $35,2 \mathrm{C} \mathrm{D} \mathrm{a}$ & $46,9 \mathrm{~A} \mathrm{~B} \mathrm{a}$ & $43,4 \mathrm{~A} \mathrm{a}$ \\
\hline $20-25$ & $19,9 \mathrm{D} \mathrm{a}$ & $36,5 \mathrm{~B} \mathrm{a}$ & $38,1 \mathrm{~A} \mathrm{a}$ \\
\hline $25-30$ & $15,3 \mathrm{D} \mathrm{b}$ & $42,8 \mathrm{~A} \mathrm{~B} \mathrm{a}$ & $27,6 \mathrm{~A} \mathrm{a} \mathrm{b}$ \\
\hline $\mathrm{CV}(\%)$ & 30,98 & 19,32 & 15,35 \\
\hline
\end{tabular}

Médias seguidas de pelo menos uma mesma letra, maiúscula na coluna e minúscula na linha, não diferem entre si pelo teste de Tukey a $5 \%$ de probabilidade.

crescimento foi de $67,5 \%$ em solo francoargilo-arenoso (JP) e de 45,5\% em solo areiafranca $(\mathrm{RC})$ (Tabela 5).

A movimentação ascendente do imazapyr ocorreu em todos os solos, sendo a ordem decrescente: areia-franca $>$ franco-argilo-arenoso $>$ muito argiloso. Solos com altos teores de argila e de matéria orgânica, ou ambos, geralmente apresentam maior adsorção e persistência de herbicidas, seguido por baixos indices de dessorção, lixiviação e degradação destes (Li et al., 2003; Hager \& Nordby, 2004; Si et al., 2006). Entretanto, esses processos ocorrem de forma distinta para cada solo e seu ecossistema, e a heterogeneidade desse meio dificulta a predição de modelos de comportamento dos herbicidas no ambiente (Pusino et al., 2004). Procópio et al. (2001) verificaram que a interação de argilominerais e compostos orgânicos do solo, com a formação de complexos adsortivos, atuou de forma diferenciada entre as frações orgânicas ou minerais. Esses autores ainda ressaltam a relevância de avaliar os fenômenos de adsorção de herbicidas e os seus riscos de lixiviação em diferentes solos.

Embora os herbicidas apresentem características moleculares distintas, as quais influenciam seu comportamento no ambiente, a matéria orgânica do solo é responsável pelo aumento adsortivo de diversos compostos e desempenha importante papel na adsorção desses produtos (Vieira et al., 1999), diminuindo a lixiviação destes no perfil dos solos (Prata et al., 2001; Regitano et al., 2001; Dyson et al., 2002). Segundo Brusseau \& Rao (1989), a matéria orgânica é o principal material adsorvente dos solos que retêm compostos iônicos e não-iônicos.

Nas condições em que foi conduzido o bioensaio, concluiu-se que o imazapyr apresenta alta mobilidade, tanto descendente como ascendente, no perfil dos três solos estudados. $O$ movimento capilar da água provoca o movimento ascendente do imazapyr no solo (lixiviação reversa), o que mantém o herbicida na região próxima à superficie do solo nos períodos de escassez de chuva. A maior movimentação do imazapyr, tanto descendente quanto ascendente, em ordem decrescente foi: solo areiafranca $>$ franco-argilo-arenoso > muito argiloso, o que pode ser associado às suas características físico-químicas distintas.

\section{LITERATURA CITADA}

BRUSSEAU, M. L.; RAO, P. S. C. The influence of sorbate organic matter interactions on sorption nonequilibrium. Chemosphere, v. 18, n. 9/10, p. 1691-1706, 1989.

COHEN, S. Z. et al. Potential for pesticide contamination of groundwater resulting from agricultural uses. In: KRUGER, R. F.; SEIBER, J. N. Treatment and disposal of pesticide wastes. Washington: American Chemistry Society, 1984. p. 297-325.

DYSON, J. S. et al. Adsorption and degradation of the weak acid mesotrione in soil and environmental fate implications.

J. Environ. Quality, v. 31, p. 613-618, 2002. 
FIRMINO, L. E. Sorção e movimento de imazapyr em três solos. 2001. 47 f. Dissertação (Mestrado em Fitotecnia) - Universidade Federal de Viçosa, Viçosa, MG, 2001.

GUSTAFSON, D. I. Groundwater ubiquity score: a simple method for assessing pesticide leachibility. Environ.

Toxicol. Chem., v. 8, n. 4, p. 339-357, 1989

HAGER, A.; NORDBY, D. Herbicide persistence and how to test for residues in soils. In: BISSONNETTE. S. Illinois agricultural pest management handbook. Illinois: University of Illinois, 2004. p. 323-326

INOUE, M. H. et al. Critérios para avaliação do potencial de lixiviação dos herbicidas comercializados no Estado do Paraná. Planta Daninha, v. 21, n. 2, p. 313-323, 2003.

LEE, A. et al. Plant metabolism. In: SHANER, D. L; O'CONNOR, S. L. (Eds.). The imidazolinone herbicides, Boca Raton: CRC Press, 1991. p.151-165.

LI, H. et al. Sorption and desorption of pesticides by clay minerals and humic acid-clay complexes. Soil Sci. Soc. Am., v. 67, p. 122-131, 2003.

LIU, S. L.; WEBER, J. B. Retention and mobility of AC 252,214, chlorsulfuron, prometryn and SD95481 in soil. Proc. Soil Weed Sci. Soc. Am., n. 38, p .465, 1985

MANGELS, G. Behaviour of the imidazolinone herbicides in soil - a review of the literature. In: SHANER, D. L.; O'CONNOR, S. L. (Eds.). The imidazolinone herbicides Boca Raton: CRC, 1991. p.191-209.

MCKINNON, J.; WEBER, J.B. Leaching and capillary movement of imazaquin in soil. Proc. Soil Weed Sci. Soc. Am., n. 41, p. 337, 1988

PRATA, F. et al. Degradação e sorção de ametrina em dois solos com aplicação de vinhaça. Pesq. Agropec. Bras., v. 36, n. 7, p. 975-981, 2001.

PROCÓPIO, S. O. et al. Sorção do herbicida atrazine em complexos organominerais. Planta Daninha, v. 19, n. 3, p. $391-400,2001$
PUSINO, A. et al. Sorption of primisulfuron on soil, and inorganic and organic soil colloids. Eur. J. Soil Sci., v. 55, p. $175-182,2004$

PUSINO, A.; PETRETTO, S.; GESSA, C. Adsorption and desorption of imazapyr by soil. J. Agric. Food Chem., v. 45, n. 3, p. 1012-1016, 1997.

REGITANO, J. B.; ALLEONI, L. R. F.; TORNISIELO, V. L. Atributos de solos tropicais e a sorção de imazaquin. Sci. Agríc., v. 58, n. 4, p. 801-807, 2001

ROSSI, C. V. S.; ALVES, P. L. C. A.; MARQUES JUNIOR, J. Mobilidade do sulfentrazone em Latossolo Vermelho e em Chernossolo. Planta Daninha, v. 23, n. 4, p. 701-710, 2005.

SI, Y. et al. Influence of organic amendment on the adsorption and leaching of ethametsulfuron-methyl in acidic soils in China. Geoderma, v. 130, p. 66-76, 2006.

SILVA, A. A.; VIVIAN, R.; OLIVEIRA Jr., R. S. Herbicidas: comportamento no solo. In: SILVA, A. A.; SILVA, J. F.

Tópicos em manejo de plantas daninhas. Viçosa, $\mathrm{MG}$ Universidade Federal de Viçosa, 2007. p. 189-248.

SILVA, C. M. M. et al. Exsudação radicular de imazapyr por mudas de eucalipto cultivadas em solução nutritiva.

R. Árvore, v. 29, n. 6, p. 915-920, 2005.

SOUZA, A. P. et. al. Lixiviação de glyphosate e imazapyr em solos com diferentes texturas e composição química IMétodo do Bioensaio. Planta Daninha, v. 18, n. 1, p. 5-16, 2000 .

SOUZA, G. V. R. et al . Exsudato radicular de imazapyr aplicado sobre mudas de diferentes clones de eucalipto. Planta Daninha, v. 24, n. 1, p. 141-147 2006.

VIEIRA, E. V. et al. Estudo da adsorção/dessorção do ácido 2,4 diclorofenoxiacético (2,4-D) em solo na ausência e presença de matéria orgânica. Química Nova, v. 22, n. 3, p. $305-308,1999$

WIDERSON, M. R.; KIM, K. D. The pesticide contamination prevention act: setting specific numerical values. Sacramento: California Department Food and Agric., Environmental Monitoring and Pest Manage, 1986. 287 p. 